\title{
Learning to Cope with Digital Technology
}

\author{
Emilia Sobolewska \\ Centre for Interaction Design \\ School of Computing \\ Edinburgh Napier University \\ +44 (0) 1314552700 \\ e.sobolewska@napier.ac.uk
}

\author{
David Benyon \\ Centre for Interaction Design \\ School of Computing \\ Edinburgh Napier University \\ +44 (0) 1314552736 \\ d.benyon@napier.ac.uk
}

\begin{abstract}
Technology surrounds people; it functions as their best friend and the worst enemy. From a trip to the local supermarket, to almost every aspect of people's professional and social lives technology is present; mediating their interactions, demanding their attention and engaging them. The main objective of this research is to understand how people learn to cope with the everyday use with the digital technology.
\end{abstract}

Keywords: Coping, Context, Throwness, Motivation, Affordances, Coping strategies, Changing praxis, Appropriation of technology, Social processes

\section{INTRODUCTION}

There is a widespread assumption, that everyone uses modern interactive technology and appreciates its liberating effects. However, according to recent reports, ten million people in UK alone have never been on-line. Whilst four million of these people belong to disadvantaged backgrounds, including unemployed $(38 \%)$, families with children $(19 \%)$ or people in advanced age (39\%), further six million describe the World Wide Web, as not suitable for them (www.raceonline2012.org). Despite that, people are often thrown into using digital technology; they face involuntary or even mandated use of it. This project aim to establish and document the range of strategies people adopt whilst learning to cope with these circumstances.

\section{THE RESEARCH BACKGROUND}

Many products and services are easier and cheaper to access via the Internet. That includes everyday goods, like food and clothing but savings that are even more significant may be done whilst purchasing air tickets and organising holidays. Furthermore, public services are also increasingly switching to online communication and information delivery. Among significant examples are: portals gathering and presenting all public services in one place (www.direct.gov.uk); portals offering help with work and pensions (www.dwp.gov.uk); portals devoted to particular Government body, like the Home Office (www.homeoffice.gov.uk); or National Health Services (http://www.nhs.uk/Pages/HomePage.aspx).

The question arises, whether it is possible to remain detached from what the Internet has to offer, or is resistance futile? How do people learn to cope with the unanticipated and sometimes involuntary use of interactive technologies? In this work it will be argued, that there are a number of circumstances, when the technology becomes an obstruction in everyday practice. The type of situations may include people expressing no interest in using technology or people who may be unable to access the required technologies in general. Further examples may include people lacking a necessary know-how to deal with the technological equipment and those who may be entirely dependent upon particular device.

There are a significant numbers of studies undertaken in a variety of similar topics, including technology acceptance in the workplace (Davis, 1989); universal design (e.g. Stephanidis, 2009); easing the way in which technology is introduced to people (e.g. Tornatzky and Klein, 1982) or an issue of 'digital divide' (Pick, Azari, 2007). However, there is currently a lack of studies of people learning to cope with the (particularly involuntary) use of interactive technology in the everyday settings.

\section{THE NOTION OF COPING}

There are different interpretations of the term "coping" in both everyday use and in the reviewed publications. The most common use of the word "cope" refers to dealing effectively with something difficult.

This common, everyday use of the word is the most popular among the literature reviewed. Papers concerned with coping are generally limited, quite dated, and are concerned with the issues of rapid changes in IT or more directly with the implementation and management of new IT services on the organisational level (Harmon, 1999, etc.). These papers are mainly concerned with coping 
mechanisms associated with the allocation of time and resources, dissemination of relevant information and resolving problems appearing during the implementation.

In this PhD work a perspective that originates in the phenomenological understanding of the issue derived from the philosophical thought of Martin Heidegger and his followers and interpreters, particularly Hubert Dreyfus (1991), and others (for example Blattner, 2008, FØllesdal, 2000, and most recently Turner, 2008, Turner and Sobolewska, 2009b) who have sought to apply his philosophy to the field of Information Technology.

In this research, the practical everyday coping will be understood as the smooth, unobtrusive use of tools. This project will aim to research how people progress from the unanticipated or even involuntary use and lack of familiarity with interactive digital devices, towards the inconspicuous, fluid use. An emphasis will be placed on the strategies that people employ whilst interacting with digital technology. Analysing these strategies is expected to provide a better understanding of the relationships that people have with the technological appliances and better understanding of the notion of coping itself.

An investigation of the relevant literature established a number of threads relevant to how people learn to cope with the digital technology. The recognised threads of coping consist of context, throwness, affordances, motivation, and emotional responses, coping strategies, changing nature of praxis, appropriation of the technology and social processes involved in practical coping. The exact relations between listed aspects are yet to be established in further reading and empirical investigation.

\subsection{Context}

The idea of context is crucial to create an adequate first - handed, engaged account of coping with the digital technology. Human skills are contextdependent, and as such, each of them should be interpreted individually, in the relation to certain circumstances within specific environment. According to Dourish (2001),

Context can mean many things, it may be the task that the system is being used to perform, the reasons for which the tasks are being carried out, the settings within which the work is conducted, or the factors that surround the user and the system (pp. 56).

\subsection{Throwness}

Throwness, as a condition of being-in-the-world, is one of the most fundamental aspects of Heideggerian philosophy. The implication introduced by Heidegger is that however peoples' existence ascertains their ability to acquire knowledge everything that people can possibly do is in fact restricted by the social environment that constitutes their everyday circumstances. Throwness is understood as an occurrence of this existence. People are thrown into the certain cultural circles, restricted by certain social norms characteristic for these circles, and further, the environment that surrounds them ultimately constitutes their actions. According to Winograd and Flores (1986),

\begin{abstract}
We do at times engage in conscious reflection and systematic thought, but these are secondary to the pre-reflective experience of being thrown in a situation in which we are always already acting. We are always engaged in acting within a situation, without the opportunity to fully disengage ourselves and function as detached observers. Even what we call 'disengagement' occurs within throwness: we do not escape our throwness, but shift our domain of concern. Our acts always happen within throwness and cannot be understood as the results of a process (conscious or non-conscious) of representing, planning, and reasoning. (pp. 71).
\end{abstract}

\subsection{Motivation}

FØllesdal (2000) provides an interesting argument with Dreyfus, concerning so-called 'absorbed coping'. In the heart of the discussion rests the issue of motivation.

For Husserl, motivation is a label for the intentional connections, the connections of sense of meaning that structure our experience. Husserl contrasts motivation with the "causal connections of nature" (pp. 252), writes FØllesdal, and furthermore, after Husserl, " $\ldots$ the willing of the end motivates the willing of the means" (Ideen I, 89, Husserliana III, 1.101.n, quoted in FØllesdal, 2000, pp. 253).

In Husserlian understanding, people are rarely aware of their motivation as it is something rarely brought into attention and however present in the consciousness, it remains unnoticed.

\subsection{Affordances}

The idea of affordances originates from Gibson (1986). Affordance can be understood as the opportunities for actions available within the certain surroundings, or in other words the relation between individual and its environment. However, the affordances do not belong specifically to either of them, but rather they constitute the result of their relationship. Further, the essence of affordances is constituted by the coupling between perception and action, as perception is not mediated by internal representations as such but is geared to be detecting and exploiting the affordance which the environment provides.

\subsection{Coping strategies}

To date, one of the coping strategies that can be recognised is a notion of familiarity. Familiarity can be understood as a readiness to cope with 
surrounding environment. For Heidegger, to be familiar is to be constantly adapting to the specific circumstances. Furthermore, Dreyfus suggests, that familiarity comprises of two main components: "know-how' and involvement. This argument was tested by Turner and Sobolewska (2009b), who argue, that evidence of "know-how" can be recognised in the form of cognitive heuristics that people employ to make sense of how to use mobile phones and to explain how they work. Moreover, they have recognised evidence of involvement in the form of comportment (an orientation towards). Turner and Sobolewska also have recognised anthropomorphising as one of the strategies that people employ during the interaction with interactive technology. Prescribing a human characteristics to an unanimated object and treating technology as friend (Reeves and Nass, 1996) or otherwise perceiving is as "magical" (Turner and Sobolewska, 2009a) seem to be a recurring theme in the literature as the way people cope with the technology.

\subsection{Changing praxis}

Dreyfus and Spinosa (1997) write about Heidegger's and Borgmann's, interpretation of technology as a way of coping with people and things that make them intelligible. The authors understand technology as a factor that negatively influences the environment and inter-human relationships in community. The only way of stopping the progressive devastation is to return to coping with simple things. The difference between thinkers is that Heidegger sees the technological developments together with the simple things, whilst Borgmann thinks that they inhibit skilful interaction. Borgmann's argument is that to create objects that people can get attach to as things, not only as the meaning they carry; they need to take advantage from their engaging capacity. In Borgmann's terms, so called focal things stand for things that are asking for attention and involvement, they desire a practice that cannot be characterised by consumption but by "engagement".

\subsection{Appropriation of technology}

The simplest understanding of appropriation is to find a new use for already existing designs. However, there are various terms that can be read, if not as synonyms of appropriation per se, definitely as a range of categories that can contribute to better understanding of the phenomena. That includes ambiguity (Gaver et al., 2003), interpretation (Sengers and Gaver, 2006), open surfaces (Höök, 2006). Furthermore, Salovaara (2008) presents, what he describes as, a cognitive account of appropriation. In his account,

Appropriation (...) is understood as an interpretation process in which the user perceives in a tool a new opportunity of action, thus acquiring a new mental usage schema that complements the existing uses. (pp. 209)

\subsection{Social processes}

The literature on the subject of social processes surrounding the notion of coping is yet to be reviewed. The discussion may be started with the statement from Dourish, that the

Computation is part of a richer fabric of relationships between people, institutions, and practices (pp. 56).

\section{SCOUT (STUDENTS COPING WITH OBLIGATORY UNIVERSITY TECHNOLOGIES)}

An initial study of coping has been undertaken to explore these characteristics of coping.

\subsection{Project design}

During their first weeks at the University, students often encounter technologies with which they are unfamiliar. In our institution, this includes a SimVenture business simulation application that is being used during practical classes within the first year core module INF07103 Information Systems in Organisations.

\subsubsection{The software}

SimVenture platform is designed to teach students about business and entrepreneurship. The simulation consists of the physical interface that represents a working environment, and the brief scenario allowing understanding the context of whole enterprise. Students need to familiarize themselves with the software on two levels, the on-screen set of different circumstances of the company and the philosophy behind the application. The simulation is driven by decisions made by the students.

\subsubsection{The predicaments}

It is possible to observe timidity, confusion, and frustration in students' interaction with new interfaces and further, trouble understanding the general underlying processes, including interdependence between decisions they make and consequences they result with. Students struggle to understand both the practical site of assignments (manipulating the interface), and to combine the philosophy behind the business simulation with the on-screen information.

\subsubsection{The methods}

The empirical work undertaken within the SCOUT was longitudinal, using a methods derived from the field of ethnography. These comprised observation, conducted during the class activities; selfassessment in the form of in-depth, semi-structured interviews; content analysis of the video recordings taken during the presentations of students' work; as 
well as other resources, including collection of relevant artefacts.

\subsubsection{Relation to recognised threads of coping}

The module chosen for this project, INF07103 Information Systems in Organisations, is an obligatory module for all the first year students within the School of Computing. Whilst undertaking the module activities, students were placed in a new, specific context (Dourish, 2001).

The hypothesis behind the empirical study refers to a number of relevant coping threats:

(i) Hypothesis I suggests that students will be thrown into studying this particular module, and their use of the proposed software will be interpreted as not of own volition.

(ii) Hypothesis II suggests that the primary motivation to learn to cope with the obligatory University technology is a passing grade (hence, it is involuntary use).

(iii) Hypothesis III suggests that students will be able to recognize affordances of the software.

(iv) Hypothesis IV suggests that students will employ a variety of strategies that will allow them to cope with obligatory University technologies.

(v) Hypothesis $V$ suggests that learning to cope with obligatory University technology involves social processes.

\section{CONCLUSIONS}

The data gathering process for the project has been recently concluded. It resolved in gathering a significant body of information, including four months of observations (three sessions, two hours each, every week); thirty-six semi-structured, in-depth interviews; fifteen hours of video recording and a collection of additional artefacts.

The primary transcription was conducted, and noticeable patterns in interviewees' utterances were recognised. The main objective is to conduct a thorough analysis and further a triangulation of gathered data. This will allow to gain a coherent understanding of how students learn to cope with compulsory university technologies, and further to obtain greater knowledge of documented themes, and to recognise which themes are the most relevant, and which may be regarded as redundant.

\section{REFERENCES}

Blattner, W., (2008) Heidegger's Being and Time, Continuum

Borgmann A., (1984) Technology and the character of contemporary life: a philosophical inquiry, Chicago, III.; London: University of Chicago Press.

Davis, F. D. (1989) Perceived usefulness, perceived ease of use, and user acceptance of information technology, MIS Quarterly, 13(3), 319-340.
Dourish, P. (2001) Where the Action Is. Cambridge, MA: MIT Press.

Dreyfus, H. L. (1991) Being-in-the-world: A Commentary on Heidegger's Being and Time, Division 1. Cambridge, MA: MIT Press.

Dreyfus, H., Spinosa, C., (1997) Highway bridges and feasts: Heidegger and Borgmann on how to affirm technology, Man and World 30, 159-177, Kluwer Academic Publishers.

FØlesdal D., (2000) Absorbed Coping, Husserl and Heidegger, in Wrathall, M. A., Malpas J. (Ed.) Heidegger, Authenticity, and Modernity, Essays in Honour of Hubert $L$. Dreyfus, Volume 1, Cambridge, Mass; London: MIT Press, pp. 251-259.

Gaver, W. W., Beaver, J., \& Benford, S. (2003) Ambiguity as a resource for design. In G. Cockton \& P. Korhonen (Eds.), CHI'03: Proceedings of the SIGCHI Conference on Human Factors in Computing Systems (p. 233-240). New York: ACM Press.

Gibson, J.J. (1986) The Ecological Approach To Visual Perception, Lawrence Erlbaum Associates, Hillsdale, NJ. (Originally published in 1979)

Harmon, C., (1999) A Small Staff Coping with Technology Replacement, Year One, SIGUCCS 99, Denver, Colorado, pp. 93-96.

Heidegger, M. (1927/1962) Being and Time. (Translated by J. Macquarrie \& E. Robinson) New York: Harper Collins.

Höök, K. (2006). Designing familiar open surfaces. In A. Mørch, K. Morgan, T. Bratteteig, G. Ghosh, \& D. Svanaes (Eds.), NordiCHI'06: Proceedings of the 4th Nordic Conference on Human-Computer Interaction (p. 242-251). New York: ACM Press.

Pick, J., B., Azari, R., (2007) Worldwide Digital Divide: Influences of Education, Workforce, Economic, and Policy Factors on Information Technology, SIGMIS-CPR'07, April 19-21, 2007, St. Louis, Missouri, USA.

Reeves, B., \& Nass, C. (1996). The media equation: How people treat computers, television and new media like real people and places. Cambridge, UK: Cambridge University Press.

Salovaara A. (2008) Inventing new uses for tools: A cognitive foundation for studies on appropriation, Human Technology, Vol. 4(2), p. 209-228.

Sengers, P., \& Gaver, B. (2006). Staying open to interpretation: Engaging multiple meanings in design and evaluation. In J. M. Carroll, S. Bødker, \& J. Coughlin (Eds.), DIS'06: Proceedings of the 6th ACM Conference on Designing Interactive systems (p. 99-108). New York: ACM Press.

Stephanidis, C. (2009) The Universal Access Handbook. Taylor and Francis.

Tornatzky, L. G. and Klein, K. J. (1982) Innovation Characteristics and Innovation Adoption-Implementation: A Meta-Analysis of Findings. IEEE Transaction on Engineering Management, 29(1), 28-45

Turner, P. (2008) Being-with: A Study of Familiarity. Interacting with Computers. 20,447-454.

Turner, P. and Sobolewska, E. (2009a) Mental Models, Magical Thinking and Individual Differences. Human Technology, 5, (1), 90-113

Turner, P., and Sobolewska, E. (2009b) Familiarity with Mobile Phones. Proc. European Conference on Cognitive Ergonomics, 221-227.

Winograd, T. and Flores, F. (1986) Understanding Computers and Cognition: A New Foundation for Design. Norwood NJ, Ablex. 